\title{
Photosynthesis of Lettuce Exposed to Different Short Term Light Qualities
}

\author{
Hyeon-Hye Kim, Raymond Wheeler, John Sager and Joey NoriKane* \\ NASA Biological Sciences Office, Mail Code: YA-E4-B, Kennedy Space Center, FL 32899, USA \\ *University of Kentucky, Biosystems and Agricultural Engineering Department, \\ Lexington, KY 40546-0276, USA
}

(Received November 15, 2004)

\begin{abstract}
The objectives of this study were to investigate the effect of short-term changes in the spectral environment on photosynthesis. Lettuce (Lactuca sativa) plant were grown under red-greenblue (RGB) light-emitting diodes (LEDs) for $23 \mathrm{~d}$ and then given 24-h exposure to red (R), redgreen $(\mathrm{RG})$, or red-blue (RB) LEDs. Photosynthetic rates $(P n)$ were measured before the $24-\mathrm{h}$ exposure, after $24-\mathrm{h}$ exposure, and $24 \mathrm{~h}$ after returning to the original RGB lighting. Temporary changes in spectral quality affected $P n$. The effects of the different light treatments on $P n$ reversed after returning to the initial light source. This study showed that $P n$ was responsive to spectral quality in the short-term and is not directly coupled to stomatal conductance.
\end{abstract}

Keywords : intercellular $\mathrm{CO}_{2}$ concentration, light-emitting diodes (LEDs), photosynthesis, stomatal conductance

\section{INTRODUCTION}

The photosynthesis and transpiration of plants could be used to provide food for the crew and recycle water and the atmosphere during long-term space missions (Mackowiak and Wheeler, 1996). Cultivating plants in space transit vehicles or in settlements on a planet's surface likely will involve the use of electric ("artificial") light sources (Sager and Wheeler, 1992). Among the lighting technologies considered for plant production in space are light-emitting diodes (LEDs) due to the small mass and volume, solid-state construction, higher degree of safety (e.g., do not use an arcdischarge approach), and long operating life (Barta et al., 1992; Bula et al., 1991).

The growth and development of plants under the light spectra produced by LEDs need to be studied and evaluated before LEDs can be accepted as a light source for growing plants in space (Goins, 2002). Lettuce is among candidate crops under consideration for use in controlled ecological life support systems proposed for human life support in space (Salisbury and Clark, 1996; Tibbitts and Alford, 1982; Wheeler et al., 2003). Several studies with lettuce using LEDs have been reported (Bula et al., 1991; Goins et al., 2001; Goins et al., 1998; Hoenecke et al., 1992; Kim et al., 2004a; Kim et al., 2004b), but none quantified the effects of spectral changes on photosynthesis. Leaf photosynthesis is of great importance for growing plants in controlled environments, but the short-term effects of light quality on photosynthesis are poorly understood.

The objectives of this investigation were to investigate the effect of short-term changes in the spectral environment on photosynthesis. The period of $24 \mathrm{~h}$ was chosen to expose the plants to one

Corresponding author: Hyeon-Hye Kim, fax: +1-321-861-2925, e-mail : hyeonhye.kim-1@ksc.nasa.gov 


\section{H.-H. KIM ET AL.}

complete diurnal interval. Examining the short-term effects enables the investigation of the effects of spectral quality without the morphological modifications induced by long-term exposure. The results will be relevant for understanding of the responses of photosynthesis to light spectra and for the design of life support systems for space travel.

\section{MATERIALS AND METHODS}

\section{Cultural conditions}

Lettuce seeds (Lactuca sativa $\mathrm{cv}$. Waldmann's Green) were planted in plastic pots $(7 \mathrm{~cm}$ tall, $164 \mathrm{~mL}$ capacity, two or three seeds per pot) containing horticultural vermiculite and Canadian sphagnum peat moss (Metro-Mix 500, The Scotts Co., Marysville, OH, USA). Sixteen pots were arranged inside of a $0.3-\mathrm{m}^{2}$ tray within a growth chamber (GC-36, Environmental Growth Chambers, Chagrin Falls, OH, USA; $6.8 \mathrm{~m}^{3}$ interior plant growth volume). At $7 \mathrm{~d}$ after planting (DAP), the lettuce seedlings were thinned to a density of 1 plant per pot. Growth chamber air temperature, relative humidity, and $\mathrm{CO}_{2}$ levels were maintained at $21 \pm 1{ }^{\circ} \mathrm{C}, 70 \pm 3 \%$, and $1,213 \pm 85$ $\mu \mathrm{mol} \mathrm{mol}{ }^{-1}(0.12 \mathrm{kPa})$, respectively. Fresh half-strength Hoagland's nutrient solution (Hoagland and Arnon, 1950; Mackowiak et al., 1989) was added daily to the bottom of each tray to supply nutrients and replenish evapotranspiration water losses.

\section{Light treatments}

The light sources were red LEDs (R), red and green LEDs (RG), red and blue LEDs (RB), and red, green, and blue LEDs (RGB). Their spectra (Fig. 1) were measured from 300-1,000 nm at 2$\mathrm{nm}$ increments with a spectroradiometer (LI-1800, LI-COR, Lincoln, NE, USA). Contributions of blue $\left(400^{-} 500 \mathrm{~nm}\right)$, green $\left(500^{-} 580 \mathrm{~nm}\right)$, yellow $\left(580^{-} 600 \mathrm{~nm}\right)$, red $\left(600^{-} 700 \mathrm{~nm}\right)$ and total photosynthetic photon flux (PPF, 400-700 nm) were determined using bandwidth integration. From the spectroradiometric data for each light treatment the yield photon flux (YPF) and the calculated amount of phytochrome in $P_{\mathrm{fr}}$ form relative to total phytochrome at photoequilibrium $\left(P_{\mathrm{f} /} / P_{\text {total }}\right)$ were determined using the method reported by Sager et al. (1988). Short-wave $(280-2,800 \mathrm{~nm})$ and thermal long-wave $\left(2,800^{-5}, 000 \mathrm{~nm}\right)$ radiation were measured with Eppley PSP and PIR radiometers (Epply Laboratories, Newport, RI, USA) (Table 1).

The $\mathrm{R}$ treatment contained 2,752 individual red LEDs mounted in a ventilated enclosure. For RG treatments, 16 Hex LEDs (NHXRGB0900000, Norlux Corp., Carol Stream, IL, USA) were

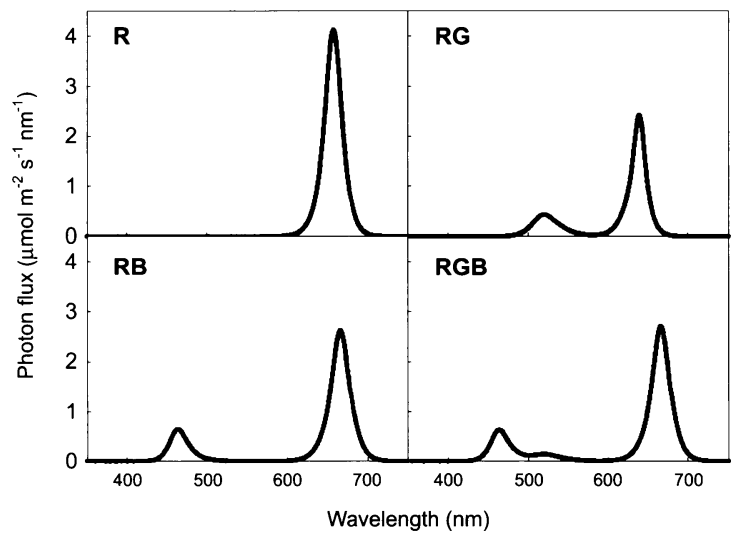

Fig. 1 Spectral distribution of light from red LEDs (R), red and green LEDs (RG), red and blue LEDs (RB), and red, green, and blue LEDs (RGB). Spectra were recorded at the top of the plant canopy with a spectroradiometer. 


\section{LIGHT QUALITY AND PHOTOSYNTHESIS}

Table 1 Spectral data for red LEDs (R), red and green LEDs (RG), red and blue LEDs (RB), and red, green, and blue LEDs (RGB). Spectra were recorded at the top of the plant canopy with a spectroradiometer.

\begin{tabular}{|c|c|c|c|c|}
\hline \multirow{2}{*}{ Parameter } & \multicolumn{4}{|c|}{ Treatment } \\
\hline & $\mathrm{R}$ & RG & $\mathrm{RB}$ & RGB \\
\hline & \multicolumn{4}{|c|}{ Photon flux $\left(\mu \mathrm{mol} \mathrm{m}{ }^{-2} \mathrm{~s}^{-1}\right)$} \\
\hline PPF $(400-700 \mathrm{~nm})$ & 100 & 100 & 100 & 100 \\
\hline Blue $\left(400^{-}-500 \mathrm{~nm}\right)$ & 0 & 2 & 19 & 18 \\
\hline Green $\left(500^{-}-580 \mathrm{~nm}\right)$ & 0 & 22 & 0 & 6 \\
\hline Yellow $(580-600 \mathrm{~nm})$ & 0 & 1 & 0 & 0 \\
\hline $\operatorname{Red}(600-700 \mathrm{~nm})$ & 100 & 75 & 81 & 76 \\
\hline Far-red $(700-800 \mathrm{~nm})$ & 0 & 0 & 1 & 1 \\
\hline \multirow[t]{2}{*}{ Yield photon flux ${ }^{2}$} & 92.8 & 86.5 & 86.1 & 87.2 \\
\hline & \multicolumn{4}{|c|}{ Ratios } \\
\hline Red: Far-red & $-^{y}$ & - & 81 & 76 \\
\hline Blue: Red & 0 & 0.03 & 0.23 & 0.24 \\
\hline Blue: Far-red & 0 & - & 19 & 18 \\
\hline \multirow[t]{2}{*}{ Calculated $P_{\mathrm{fr}} / P_{\text {total }}{ }^{2}$} & 0.88 & 0.89 & 0.86 & 0.87 \\
\hline & \multicolumn{4}{|c|}{ Irradiance $\left(\mathrm{W} \mathrm{m}^{-2}\right)$} \\
\hline $280-2,800 \mathrm{~nm}$ & 17 & 19 & 18 & 20 \\
\hline $2,800-50,000 \mathrm{~nm}$ & 9 & 18 & 1 & 6 \\
\hline
\end{tabular}

${ }^{2}$ Calculated according to Sager et al. (1988).

${ }^{y}$ Undefined.

mounted in a separate ventilated enclosure. Each Hex LED contained 30 red, 30 green, and 30 blue LEDs. The RB treatment consists of nine LED arrays (Snap-Lite ${ }^{\mathrm{TM}}$, Quantum Devices, Inc., Barneveld, WI, USA) equipped with red and blue LEDs. Each array contained 150 red and 75 blue individual diodes. For RGB treatment, four green Hex LEDs (NHX530040S00S, Norlux Corp., Carol Stream, IL, USA) were mounted between the nine arrays of red and blue LEDs. The green LED supplied $6 \%$ of the total PPF.

The light treatments all had PPF's of $100 \mu \mathrm{mol} \mathrm{m}^{-2} \mathrm{~s}^{-1}$ with an 18 -h photoperiod, producing 6.5 $\mathrm{mol} \mathrm{m} \mathrm{m}^{-2} \mathrm{~d}^{-1}$. The PPF levels were measured at the top of the plant canopy with a quantum sensor (LI-190SA, LI-COR, Lincoln, NE, USA).

\section{Plant measurements}

Lettuce plants were grown under RGB for $23 \mathrm{~d}$ and then given 24-h exposure to R, RG, or RB. Photosynthetic rates were measured three different days between 2.5 and $3.5 \mathrm{~h}$ after lights came on before the 24-h exposure (23 DAP), after 24-h exposure (24 DAP), and $24 \mathrm{~h}$ after returning to the original RGB lighting (25 DAP).

Photosynthetic rates $(P n)$ were measured from four of the youngest fully expanded leaves per treatment using a portable photosynthesis system (LI-6400, LI-COR, Lincoln, NE, USA). During all measurements the leaf temperature, relative humidity, and $\mathrm{CO}_{2}$ levels within the cuvette were set at $21^{\circ} \mathrm{C}, 70 \%$, and $1,200 \mu \mathrm{mol} \mathrm{mol}^{-1}$, respectively. The conditions in the cuvette were allowed

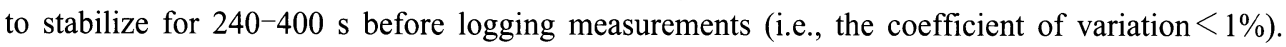
The leaf temperatures were $21.1 \pm 0.4^{\circ} \mathrm{C}, 21.2 \pm 0.6^{\circ} \mathrm{C}, 21.8 \pm 0.5^{\circ} \mathrm{C}$, and $21.9 \pm 0.5^{\circ} \mathrm{C}$ under $\mathrm{R}$, $\mathrm{RG}, \mathrm{RB}$, and RGB, respectively.

All plants were harvested after the photosynthesis measurements at 25 DAP. The physiological parameters recorded were the number of leaves greater than $1 \mathrm{~cm}$ in length, longest leaf length, shoot fresh mass (shoot FM), shoot dry mass (shoot DM), and leaf area. Plant tissue samples were dried in a drying oven for $48 \mathrm{~h}$ at $70^{\circ} \mathrm{C}$ before weighing. 
Statistical analysis

The experiment was repeated three times with means calculated using data from four plants per repetition. Statistical analysis was subjected to analysis of variance followed by Duncan's multiple range tests using $5 \%$ as the level of significance (SPSS Inc., Chicago, IL, USA).

\section{RESULTS AND DISCUSSION}

The light sources used in this study were all LEDs and had narrow spectral bands (23-35 nm band width at half peak height) in each red, blue, and green region of waveband (Fig. 1). The YPF was highest for R, followed by RGB and then RG and RB. The calculated $P_{\mathrm{f} /} / P_{\text {total }}$ values for all the treatments were between 0.86 and 0.89 . There was very little far-red radiation present among spectral environments with the highest amount of far-red originated from the RB and RGB being $1 \mu \mathrm{mol} \mathrm{m} \mathrm{m}^{-1}$ (Table 1). This suggests that the phytochrome photostationary state difference among treatments was negligible.

Figure 2 shows photosynthetic rates $(P n)$, stomatal conductance $(g s)$, and intercellular $\mathrm{CO}_{2}$ concentration $(\mathrm{Ci})$ of lettuce leaves grown under RGB for $23 \mathrm{~d}$ and then exposed to R, RG, or RB for $24 \mathrm{~h}$. Initial average $P n$ measured before the 24-h exposure was $5.5 \pm 1.4 \mu \mathrm{mol} \mathrm{CO} \mathrm{Cm}^{-2} \mathrm{~s}^{-1}$.

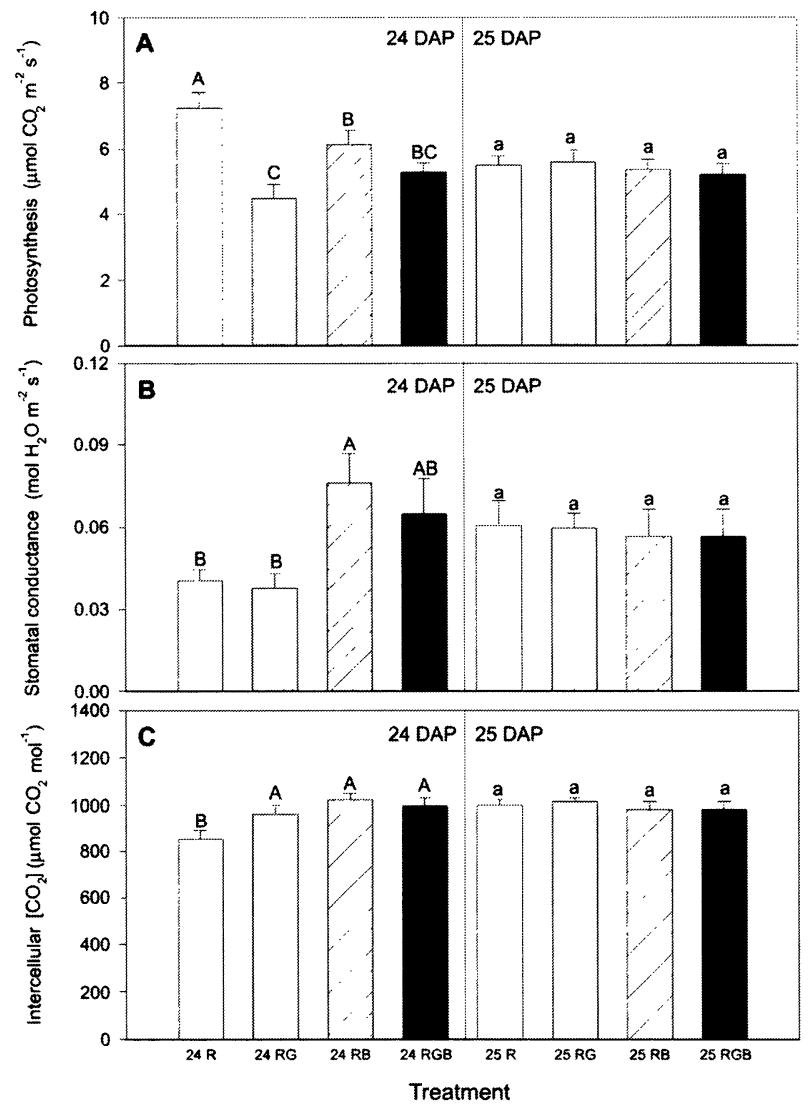

Fig. 2 Photosynthetic rates (A), stomatal conductance (B), and intercellular $\mathrm{CO}_{2}$ concentration (C) of lettuce leaves grown under red, green, and blue LEDs (RGB) for $23 \mathrm{~d}$ and then exposed for $24 \mathrm{~h}$ to red LEDs (R), red and green LEDs (RG), or red and blue LEDs (RB). Measurements were taken after 24-h exposure (24 DAP) and $24 \mathrm{~h}$ after returning to the initial RGB lighting (25 DAP). Data represent means $\pm \mathrm{SE}$ of 12 measurements. 


\section{LIGHT QUALITY AND PHOTOSYNTHESIS}

The $P n$ values were different after 24-h exposures to different spectral qualities, with maximum $P n$ under R and minimum under RG, although the difference between RG and RGB was not statistically significant. However, these effects were reversible, since $P n$ were the same $24 \mathrm{~h}$ after returning to the original RGB lighting regardless of previous treatments (Fig. $2 \mathrm{~A}$ ). Initial average $g s$ measured before the 24-h exposure was $0.075 \pm 0.024 \mathrm{~mol} \mathrm{H}_{2} \mathrm{O} \mathrm{m}^{-2} \mathrm{~s}^{-1}$. After 24-h exposure, $g s$ was highest under RB, followed by RGB, and then R and RG, although the differences between RB and RGB, and among R, RB and RGB were not statistically significant. Twenty-four hours after returning plants to the original RGB light there was no significant difference among treatments (Fig. 2B). Initial average $C i$ measured before the 24-h exposure was $1,050 \pm 39 \mu \mathrm{mol} \mathrm{CO}_{2} \mathrm{~mol}^{-1}$. After 24-h exposure, $C i$ was lower under R than under RG, RB, RGB. As shown in $P n$ and $g s$, these effects were reversible $24 \mathrm{~h}$ after returning plants back to the RGB light under which they were grown (Fig. 2C).

In the previous study, lettuce was grown under 4 different light qualities: (1) red and blue LEDs, (2) red and blue LEDs with green fluorescent lamps, (3) green fluorescent lamps, or (4) cool-white fluorescent lamps (Kim et al., 2004a). Compared to other light treatments, the $P n$ were lower in plants grown under green fluorescent lamps. However, specific leaf area was greatest in plants grown under green fluorescent lamps, i.e., they had thinner leaves (Kim et al., 2004a). Consequently, photomorphogenic responses to light quality could influence total plant $P n$ through altering light capture by leaves, without directly affecting $P n$ per unit leaf area.

Such modifications in leaf morphology in response to different spectral qualities during growth confound the interpretation of the spectral effects. Investigating the effects of spectral quality on $P n$ without the morphological modifications is possible by growing plants under the same lighting conditions before temporarily exposing the plants to different light treatments. This was done in the present study by growing lettuce plants under RGB for $23 \mathrm{~d}$, then exposing them for $24 \mathrm{~h}$ to R, RG, or RB, and then returning to the initial RGB lighting. The $P n, g s$, and $C i$ were different after 24-h exposure to different spectral qualities and these effects were reversible after returning to the original lighting under which the plants were grown.

Yorio et al. (2001) compared lettuce plants grown under 3 different light conditions: (1) red LEDs, (2) red LEDs and blue fluorescent lamps, or (3) cool-white fluorescent lamps. As a result, the $P n$ were similar in all treatments, although gs was lower in plants grown under red LEDs than other light treatments. The experimental approach of that study was different from the present study, since Yorio et al. (2001) studied lettuce plants "grown under" different light qualities. In the present study, the $P n$ were highest in plants temporarily "exposed to" R for 24 h, although gs was lower than other treatments.

Tennessen et al. (1994) grew Pueraria lobata under metal halide and incandescent lamps and measured the photosynthesis under red LEDs and a xenon arc lamp over the range of $0-1,500 \mu \mathrm{mol}$ $\mathrm{m}^{-2} \mathrm{~s}^{-1} \mathrm{PPF}$. Net photosynthesis rates were higher under red LEDs at low PPF, i.e., $<175 \mu \mathrm{mol}$ $\mathrm{m}^{-2} \mathrm{~s}^{-1}$, but were lower at higher PPF compared to the rates from plants under the xenon arc lamp (Tennessen et al., 1994). Similar observations were made in the present study, where the PPF was only $100 \mu \mathrm{mol} \mathrm{m}^{-2} \mathrm{~s}^{-1}$ and the $P n$ was highest when the plants were exposed to the red LED treatment.

By manipulating photosynthetic capacity using antisense RNA technology, the commonly observed correlation between $P n$ and gs could be disrupted (von Caemmerer et al., 2004). The stomatal conductance did not correlate with photosynthetic capacity in transgenic tobacco with reduced amounts of Rubisco (von Caemmerer et al., 2004). In that study, light was increased from 100 to $1,000 \mu \mathrm{mol} \mathrm{m}^{-2} \mathrm{~s}^{-1}$ for $30-40 \mathrm{~min}$ and then returned to $100 \mu \mathrm{mol} \mathrm{m}^{-2} \mathrm{~s}^{-1}$, so the quantity of light was modified. In the present study, the quality of light was modified for $24 \mathrm{~h}$ and then plants were returned to original lighting conditions. The data after 24-h exposure to red LED light demonstrated that the $P n$ was not tightly linked to the $g s$, while the data after returning to original 


\section{H.-H. KIM ET AL.}

lighting conditions showed the commonly observed correlation between $P n$ and $g s$.

Experimentally, stomata, which have achieved their steady-state aperture under red light irradiation, open wider when exposed to additional weak blue light (Assmann, 1988; Ogawa et al., 1978). In addition, green light reversal of blue-light-stimulated stomatal opening occurs in a number of species, including Vicia faba, Commelina communis, Pisum sativum, Nicotiana glauca, Arabidopsis thaliana, N. tabacum, Allium cepa, and Hordeum vulgare (Frechilla et al., 2000; Talbott et al., 2002). In our study, the experimental approach was different from Frechilla et al. (2000) and Talbott et al. (2002), who studied stomatal responses of epidermal strips, however, the stomatal responses to spectral quality were similar with the maximum $g s$ in plants exposed to RB and the minimum $g s$ in plants exposed to RG.

Compared to $g s, C i$ had better correlation with $P n$ when the spectral environments changed. Plants exposed to R operated at relatively lower $C i$ because of the relatively higher $P n$ and plants exposed to RG, RB, or RGB operated at relatively higher $\mathrm{Ci}$ because of the relatively lower $P n$.

Stomatal movements can be affected by various environmental factors, including plant water status, $\mathrm{CO}_{2}$ concentration, and light (Raschke, 1975). For example, bright light and low concentration of $\mathrm{CO}_{2}$ stimulated stomata opening, while high $\mathrm{CO}_{2}$ concentration even in bright light, caused closure (Raschke, 1975; Scarth, 1932). Generally, stomata respond to changes in intercellular $\mathrm{CO}_{2}$ concentration rather than ambient $\mathrm{CO}_{2}$ concentration $(\mathrm{Ca})$ (Mott, 1988; von Caemmerer et al., 2004). In the present study, $\mathrm{Ca}$ did not vary greatly, so the stomatal $\mathrm{CO}_{2}$ response would more likely be related to the $C i$. However, the decreased $C i$ resulted from the increased $P n$ in plants exposed to red LED light did not appear to be perceived by guard cells, as gs was relatively lower in plants exposed to the red light. This observation is similar to that of experiments using transgenic plants with varying decreases in photosynthetic capacity. In those plants, when $P n$ was reduced $C i$ increased, but gs showed little change (von Caemmerer et al., 2004).

The physiological measurements from all treatments; leaf number, the longest leaf length, shoot FM, shoot DM, and leaf area; were not significantly different among lettuce plants grown under RGB for $23 \mathrm{~d}$, and exposed to R, RG, or RB for $24 \mathrm{~h}$, and then returned to the initial RGB lighting (data not shown). This indicated that the 24-h exposure to different light qualities had minimal affect on plant growth.

In conclusion, this investigation demonstrated that temporary changes in spectral quality affected $P n$. The effects of the different light treatments on $P n$ reversed after returning to the initial light source. Especially for very specialized applications, such as long-term space missions, the effects of light spectrum observed on plant production must be incorporated into the design of spectrally balanced LED systems for supporting plant growth.

This work was performed while the first author held a National Research Council Research Associateship Award at NASA Kennedy Space Center. We thank Johnny Burrows, Larry Koss, Holly Loesel, and Charles Quincy for their support. Mention of a trade name or proprietary product does not constitute an endorsement, guarantee, or warranty by National Aeronautics and Space Administration. Quantum Devices, Inc., Barneveld, WI, USA, holds a patent (No. 5,012,609) on light-emitting diodes as an illumination source for plant growth.

\section{REFERENCES}

Assmann, S. M. 1988. Enhancement of the stomatal response to blue light by red light, reduced intercellular concentrations of $\mathrm{CO}_{2}$ and low vapor pressure differences. Plant Physiol. 87: 226-231.

Barta, D. J., Tibbits, T. W., Bula, R. J., Morrow, R. C. 1992. Evaluation of light emitting diode characteristics for space-based plant irradiation source. Adv. Space Res. 12: 141-149.

Bula, R. J., Morrow, R. C., Tibbits, T. W., Barta, D. J., Ignatius, R. W., Martin, T. S. $1991 . \quad$ Light-emitting diodes as a radiation source for plants. HortScience 26: 203-205.

Frechilla, S., Talbott, L. D., Bogomolni, R. A., Zeiger, E. 2000. Reversal of blue light-stimulated stomatal 


\section{LIGHT QUALITY AND PHOTOSYNTHESIS}

opening by green light. Plant Cell Physiol. 41: 171-176.

Goins, G. D. 2002. Growth, stomatal conductance, and leaf surface temperature of Swiss chard grown under different artificial lighting technologies. Soc. Automot. Engr. Tech. Paper 2002-01-2338.

Goins, G. D., Sager, J. C., Wheeler, R. M., Ruffe, L. M., Yorio, N. C. 2001. Salad crop production under different wavelengths of red light-emitting diodes (LEDs). Soc. Automot. Engr. Tech. Paper 2001-012422.

Goins, G. D., Yorio, N. C., Vivenzio, H. 1998. Performance of salad-type plants using lighting and nutrient delivery concepts intended for spaceflight. J. Aerospace 107: 284-289.

Hoagland, D. R., Arnon, D. I. 1950. The water culture method for growing plants without soil. California Agric. Exp. Stn. Circular 347.

Hoenecke, M. E., Bula, R. J., Tibbitts, T. W. 1992. Importance of 'blue' photon levels for lettuce seedlings grown under red-light-emitting diodes. HortScience 27: 427-430.

Kim, H. H., Goins, G. D., Wheeler, R. M., Sager, J. C. 2004a. Green light supplementation for enhanced lettuce growth under red- and blue-light -emitting diodes. HortScience 39: 1617-1622.

Kim, H. H., Goins, G. D., Wheeler, R. M., Sager, J. C. 2004b. Stomatal conductance of lettuce grown under or exposed to different light qualities. Ann. Bot. 94: 691-697.

Mackowiak, C. L., Owens, L. P., Hinkle, C. R., Prince, R. O. 1989. Continuous hydroponic wheat production using a recirculating system. NASA Tech. Memo. 102784.

Mackowiak, C. L., Wheeler, R. M. 1996. Growth and stomatal behavior of hydroponically cultured potato (Solanum tuberosum L.) at elevated and superelevated $\mathrm{CO}_{2}$. J. Plant Physiol. 149: 205-210.

Mott, K. A. 1988. Do stomata response to $\mathrm{CO}_{2}$ concentrations other than intercellular? Plant Physiol. 86: 200-203.

Ogawa, T., Ishikawa, H., Shimada, K., Shibata, K. 1978. Synergistic action of red and blue light and action spectra for malate formation in guard cells of Vicia faba L. Planta 142: 61-65.

Raschke, K. 1975. Stomatal action. Annu. Rev. Plant Physiol. 26: 309-340.

Sager, J. C., Smith, W. O., Edwards, J. L., Cyr, K. L. 1988. Photosynthetic efficiency and phytochrome photoequilibria determination using spectral data. Trans. ASAE 31: 1882-1889.

Sager, J. C., Wheeler, R. M. 1992. Application of sunlight and lamps for plant irradiance in space bases. Adv. Space Res. 12: 133-140.

Salisbury, F. B., Clark, M. A. 1996. Suggestions for crops grown in a controlled environment life-support systems, based on attractive vegetarian diets. Adv. Space Res. 18: 33-39.

Scarth, G. W. 1932. Mechanism of the action of light and other factors on stomatal movement. Plant Physiol. 7: 481-504.

Talbott, L. D., Nikolova, G., Ortiz, A., Shmayevich, I., Zeiger, E. 2002. Green light reversal of blue-lightstimulated stomatal opening is found in a diversity of plant species. Am. J. Bot. 89: 366-368.

Tennessen, D. J., Singsaas, E. L., Sharkey, T. D. 1994. Light-emitting diodes as a light source for photosynthesis research. Photosynth. Res. 39: 85-92.

Tibbitts, T. W., Alford, D. K. 1982. Controlled ecological life support system - use of higher plants. NASA Conf. Pub. 2231.

von Caemmerer, S., Lawson, T., Oxborough, K., Baker, N. R., Andrews, T. J., Raines, C. A. 2004. Stomatal conductance does not correlate with photosynthetic capacity in transgenic tobacco with reduced amounts of Rubisco. J. Exp. Bot. 55: 1157-1166.

Wheeler, R. M., Sager, J. C., Prince, R. P., Knott, W. M., Mackowiak, C. L., Stutte, G. W., Yorio, N. C., Ruffe, L. M., Peterson, B. V., Goins, G. D., Hinkle, C. R., Berry, W. L. 2003. Crop production for advanced life support systems - Observations from the Kennedy Space Center breadboard project. NASA Tech. Memo. 2003-211184.

Yorio, N. C., Goins, G. D., Kagie, H. R., Wheeler, R. M., Sager, J. C. 2001. Improving spinach, radish, and lettuce growth under red light-emitting diodes (LEDs) with blue light supplementation. HortScience 36: 380-383. 